\title{
Sismik Yüklere Maruz Yap1-Zemin Ortak Sisteminin Çözüm Sürecinde Temel-Zemin Etkileşiminin Sönümü
}

\author{
Mustafa Yavuz Çetinkaya, Erkan Çelebi, Osman Kırtel \\ Fen Bilimleri Enstitüsü, Sakarya Üniversitesi, Sakarya, 54187, Türkiye \\ Mühendislik Fakültesi, Sakarya Üniversitesi, Sakarya, 54187, Türkiye \\ Teknoloji Fakültesi, Sakarya Üniversitesi, Sakarya, 54187, Türkiye
}

\begin{abstract}
Özet- Bu çalışmanın amacı, yapı-zemin ortak sisteminin sismik yükler altında karşılıklı etkileşimini ve zemin mekanik özelliklerinin üstyapıların dinamik davranışı üzerindeki etkilerini, altsistem yaklaşımıyla temel-zemin arakesitinde tanımlanan dinamik rijitlik fonksiyonlarına bağlı değerlendirmek, temel ortamında olușan ilave sönümün sayısal sonuçlar üzerindeki etkisini yönetici parametrelere bağlı tartışmaktır.
\end{abstract}

\section{Anahtar Kelimeler- Yapı-Zemin Etkileşimi; Temel Ortamının Sönümü̈}

\begin{abstract}
The goal of this study is to evaluate the effect of the soil-structure dynamic interaction and the mechanical properties of the underlying soil on the dynamic response of the superstructure by using the sub-structure method based on impedance functions at the foundation-soil interface. Furthermore, the influence of the additional foundation damping on the computational results depending on governing parameters is discussed.
\end{abstract}

Keywords- Soil-Structure Interaction; foundation damping

\section{GİRIŞ}

S smik yüklere karşı dinamik davranışlarının gerçeğe daha yakın olarak izlenmek istenmesi durumundaki nükleer güç santralleri, viyadükler, masif köprü ayakları, barajlar ve çok katlı binalar gibi rijit temelli önemli yapı sistemleri, günümüzde zorunlu olarak depremselliği yüksek bölgelerde özellikle yumuşak zemin koşullarında inşa edilmek zorunda kalabilirler. Yapı-zemin dinamik etkileşim probleminin sismik analizi; üstyapı, yapı temeli ve temelin çevresini saran zemin olmak üzere ayrı karakterdeki üç sistemin ortak titreşimine dayalı yapısal tepkiyi ortaya çıkarmayı hedeflemektedir. Zemin koşullarının yapısal davranış üzerindeki etkisinin kontrol parametrelere bağlı incelenmesinde, doğrudan çözüm yöntemi [1-3] ve altsistem yaklaşımı [4-7] kullanılmaktadır. Yapıların dinamik davranışının analizinde yerel zemin koşullarının etkisinin hesap ilkelerine doğrudan katılması hususunda yakın zamanda önemli birçok araştırma raporu yayınlanmıştır [8-9].
$\mathrm{Bu}$ raporlarda proje mühendislerinin kullanımına sunulan basitleştirilmiş çözüm yöntemleri aslında yapı-zemin etkileşim problemleriyle ilgili gerçekleştirilmiş olan kapsamlı teorik çalışmaların ve tecrübelerin sentezine dayanmaktadır.

$\mathrm{Bu}$ çalışmanın amacı, zeminin mekanik özelliklerinin üstyapıların dinamik davranışı üzerindeki etkilerini, altsistem yaklaşımıla yapı temeli-zemin arakesitinde tanımlanan dinamik rijitlik fonksiyonlarına bağlı değerlendirmek, temel ortamında oluşan ilave sönüm etkisinin periyot uzamasına bağlı değişimini, eylemsizlik etkileşimi koşulu altında tartışmaktır. Kapsamlı parametrik araştırmalar için farklı ölçeklerde köprü ayağı temelleri, üstyapı narinlikleri ve temel gömülme derinlikleri kullanılmıştır. Örnek modelin temel-zemin arakesitinde zemin ortamının şekil değiştirme özelliğini ve sönümünü temsil eden titreşim frekansına bağl1 yaylar ve söndürücüler dikkate alınmıştır.

\section{II. ÇÖZÜM YÖNTEMİ}

\section{Zemin Etkileşimli Yapı Periyodu}

Titreşen bir yapıda oluşan eylemsizlik etkileri, yapı-zemin sisteminin karşılıklı etkileşiminden dolayı oluşturduğu kesme kuvveti ve moment sonucunda yap1 temelinin ötelenmesine ve dönmesine neden olmaktadır. Bu yerdeğiştirmeler tüm sistemin sönümünü ve periyodunu önemli derece değiştirecek olan histeresiz zemin sönümü ve radyasyon sönümünün ortak etkisiyle titreşim enerjisinin tüketilmesine yol açmaktadır. Yap1 temelinin, oturduğu zemine mesnetlenme şekli ve davranışı ile ilgili iki farklı yaklaşım mevcuttur:

- Rijit Taban Yaklaşımı: Temelin oturduğu zemin ortamının sonsuz rijit kabul edilmesi durumunda üstyapının dış yük etkisi altında sadece ötelenme yaptığı gözlemlenir (Şekil 1a).

- Esnek Taban Yaklaşımı: Zemin ortamının şekil değiştirmesi söz konusu olduğunda temelin dönmesi ve ötelenmesi sonucunda üstyapının toplam yerdeğiştirmesinin değiştiği gözlemlenir (Şekil 1b). 


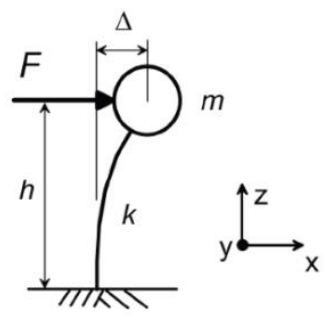

(a)

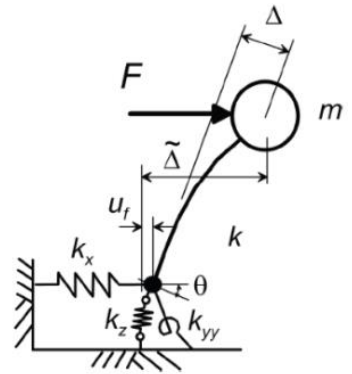

(b)

Şekil 1. Üstyapının kuvvet etkisinde yaptığı deformasyonlar: (a) zemine rijit bağlı durumda ötelenme (b) esnek temel ortamından kaynaklanan dönme ve ötelenmeler [8].

Şekil 1 a'da verilen rijit tabanlı yapı sisteminin periyodu:

$$
T=2 \pi \sqrt{\frac{m}{k}}
$$

Şekil 1 b'de verilen esnek tabanlı yapı sisteminin periyodu:

$$
\tilde{T}=2 \pi \sqrt{\frac{m}{k}+\frac{m}{k_{x}}+\frac{m h^{2}}{k_{y y}}}
$$

Esnek tabanlı ve rijit tabanlı yapı sistemlerinin periyotlarının oranı:

$$
\frac{\tilde{T}}{T}=\sqrt{1+\frac{k}{k_{x}}+\frac{k h^{2}}{k_{y y}}}
$$

ifadesi ile elde edilir [10]. Yapı-zemin etkileşimini dolayısıyla $\tilde{T} / T$,yi kontrol eden anahtar parametreler aşağıda verilmişsir [11-12]:

$$
\frac{h}{V_{s} T}, \frac{h}{B}, \frac{L}{B}, \frac{m}{\rho_{s} 4 B L h} \text { ve } v
$$

Burada $h$ modal yapı yükseliğidir, $B$ ve $L$ sırasıyla temel yarı genişliği ve temel yarı uzunluğudur, $\rho_{\mathrm{s}}$ zemin birim hacim kütlesi, $v$ zeminin poisson oranı, $h / B$ yapı modal yüksekliğinin temel yarı genişliğine oranı, $B / L$ temel yarı genişliğinin temel yarı uzunluğa oranı, $m /\left(\rho_{s} 4 B L h\right)$ yapı modal yüksekliğine eşit bir derinlikteki üstyapı kütlesinin zeminin kütlesine oranıdır. Kütle oranının etkisi küçüktür ve bu değer genellikle 0.15 alınabilir [10]. $h /\left(V_{s} T\right)$ yapının zemine rijitlik oranı olarak tanımlanır [8]. Burada, $h /\left(V_{s} T\right)$ oranının 0.1 'den büyük olması durumunda, eylemsizlik etkileşimine bağlı yapı-zemin etkileşimi, bina yapısının periyodunu ve sistemin sönümü önemli derecede değiştirebilmektedir. Bu durum tasarım kesme kuvvetini ve sonucunda yapının deformasyon talebini zemine rijit bağlı yapıya kıyasla farklılaştıracaktır. Ayrışmış kaya zeminde, perde duvar ve çaprazlı yapılar için bu oran yaklaşık olarak 0.1 ve 0.5 arasında değişmektedir [13].

\section{Temel Sönümü}

Dış yük etkisi altında esnek tabanlı bir yapıda, periyodun artmasına ek olarak temel-zemin etkileşimiyle birlikte ilave bir sönüm ortaya çıkar ve bu sönüme temel sönümü $\left(\beta_{f}\right)$ adı verilir. Temel sönümü iki parçadan oluşur (1) zeminin birim şekil değiştirmesine bağlı olarak meydana gelen sönüm katkısı (histeresiz sönüm) ve (2) zemin ortamının sınırsızlığı nedeniyle enerji kaybına eşdeğer anlamda karşı gelen fiktif zemin sönümü diğer bir adıyla geometrik sönümdür. Temel sönümünün tanımlanması için geliştirilen birçok analitik yaklaşımdan bir tanesi de Wolf (1985) tarafından önerilen formülasyondur [14].

$\beta_{f}=\left[\frac{(\tilde{T} / T)^{n_{s}}-1}{(\tilde{T} / T)^{n_{s}}}\right] \beta_{s}+\frac{1}{\left(\tilde{T} / T_{x}\right)^{n_{x}}} \beta_{x}+\frac{1}{\left(\tilde{T} / T_{y y}\right)} \beta_{y y}$

Denklem (5)'de $\beta_{s}$ zemin histeresiz sönümü, $\beta_{x}$ ve $\beta_{y y}$ sırasıyla ötelenme ve dönme titreşim modları için geometrik sönümdür. $T_{x}$ ve $T_{y y}$ fiktif titreşim periyotlarıdır. Eğer titreşim kaynağ 1 sadece ötelenme ve dönme yapıyorsa fiktif titreşim periyotlar1;

$T_{x}=2 \pi \sqrt{\frac{m}{k_{x}}} \quad T_{y y}=2 \pi \sqrt{\frac{m h^{2}}{k_{y y}}}$

formülleriyle hesaplanır. Denklem (5)'de kullanılan $n_{s}, n_{x}$ ve $n_{y y}$ katsayılarının 2 alınması önerilir [15]. Hesap edilen temel sönümü $\beta_{f}$ 'e üstyapının sönümünün eklenmesiyle esnek tabanlı yapı sisteminin sönümü;

$\beta_{0}=\beta_{f}+\frac{1}{(\tilde{T} / T)^{n}} \beta_{i}$

elde edilir. Denklem (7)' de $(\tilde{T} / T)^{n}$ ifadesinde $n$, doğrusal viskoz yapı sönümü için 3 aksi durumları için 2 alınması önerilir [15].

\section{Dikdörtgen Rijit Temellerin Empedans Fonksiyonları}

Empedans fonksiyonları temel-zemin etkileşiminin frekansa bağlı sönüm ve rijitlik karakterlerini temsil eder. Klasik çözümler, kompleks değerli empedans fonksiyonu için şu şekilde yazılabilir [16-17]:

$\bar{k}_{j}=k_{j}+i \omega c_{j}$

Burada $\bar{k}_{j}$ empedans fonksiyonunu, $j$ ise ötelenme $(x, y, z)$ ve dönme $(x x, y y, z z)$ modlarını ifade eder. $k_{j}$ ve $c_{j}$ sırasıyla 
temelin dinamik rijitliğini ve sönüm katsayısını gösterir. Denklem (8) için alternatif bir form;

$$
\bar{k}_{j}=k_{j}\left(1+2 i \beta_{j}\right)
$$

ifadesi ile verilir. Denklemde, zeminin birim şekil değiştirmesine bağlı olarak meydana gelen histeresiz sönüm ve zemin ortamının sınırsızlığı nedeniyle enerji kaybına eşdeğer anlamda karşı gelen geometrik sönümün toplamını tanımlayan $\beta_{j}$;

$\beta_{j}=\frac{\omega c_{j}}{2 k_{j}}$

formülü ile elde edilir.

Dinamik rijitlik $\left(k_{j}\right)$; temel boyutları $(B$ ve $L)$, zemin kayma modülü $(G)$, zemin poisson oranı $(v)$, dinamik düzeltme katsayısı $\left({ }^{\alpha_{j}}\right)$ ve gömülme katsayısının $\quad\left({ }^{\eta_{j}}\right)$ bir fonksiyonudur.

$k_{j}=K_{j} \alpha_{j} \eta_{j}$

$K_{j}=G B^{m} f(B / L, v), \alpha_{j}=\alpha_{j}\left(B / L, a_{0}\right)$

$\eta_{j}=f(B / L, D / B)$

Denklem (11)'de $K_{j}, j$ modu için frekanstan bağımsız temel statik rijitliğidir. $B$ ve $L$ sirasılya temel yarı genişliği ve temel yarı uzunluğu, $\eta$ ise temel tipinin gömülü olması durumunda gömülme derinliği $(D)$ ve temel en-boy oranına $(B / L)$ bağlı olarak hesap edilen katsayıdır. Ötelenme ve dönme modu için sirasıyla $m$ değerleri 1 ve 3 alınmaktadır [4]. Dinamik düzeltme katsayısı $\left(\alpha_{j}\right)$ boyutsuz frekans parametresi $a_{0}$ 'a bağlı olarak;

$a_{0}=\frac{\omega B}{V_{s}}$

elde edilir. Zaman tanım analizi için $a_{0}$, a bağlı olan temel yay ve sönüm katsayıları için tek bir açısal frekans $\omega$ seçilir. $\mathrm{Bu} \omega$ seçilirken esnek tabanlı yapının baskın tepkisinin oluşacağı andaki açısal frekans $\bar{\omega}$ kullanılabilir [8]. Frekansa bağlı olan temel dinamik rijitliklerinin hesaplanmasında kullanıcak $\bar{\omega}$ iterasyon yapılarak hesaplanabilir[10]. Elastik bir yarı-uzaya oturan dikdörtgen rijit temellerin empedans fonksiyonlarının hesabı için ampirik bağıntılar literatürde mevcuttur [4]. Yüzeysel ve gömülü dikdörtgen temeller, şematik olarak Şekil 2'de verilmiştir.

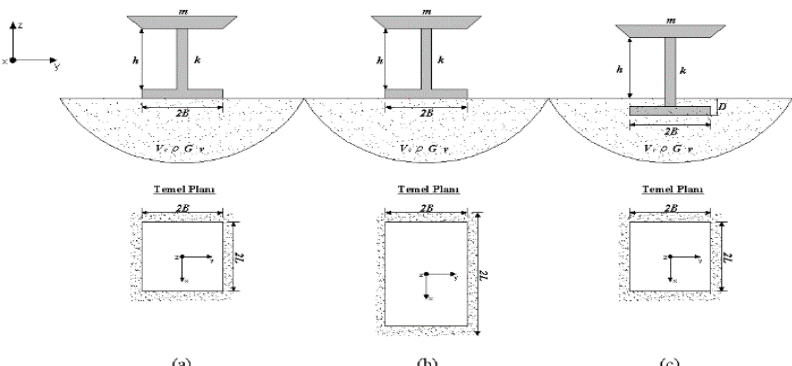

(a)

(b)

Şekil 2. Didörtgen temel tipleri: (a) yüzeysel temel (b) gömülü temel [8].

\section{PARAMETRIKK ÇALIȘMA}

Bu bölümde tek serbestlik dereceli sistemi temsil eden bir köprü ayağı modelinin farklı rijitliklerinde periyot oranı $(\tilde{T} / T)$ ve temel ortamının sönümü $\left(\beta_{f}\right)$ elde edilmiştir. Örnek modelin şematik gösterimi, analizlerde hangi temel tipi ve geometrisinin dikkate alındığı Şekil 3'de verilmektedir.

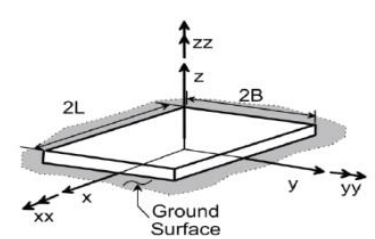

(a)

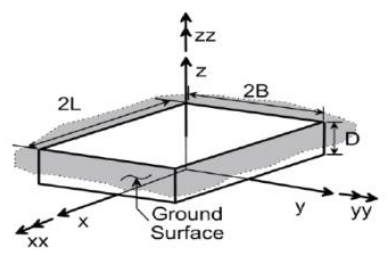

(b)
Şekil 3. Farklı temel tip ve geometrilerine sahip köprü ayağı modelleri: (a) yüzeysel kare temel (b) yüzeysel dikdörgen temel (c) gömülü kare temel

Şekil 3'de verilen köprü ayă̆ı-zemin sistemlerinin $\tilde{T} / T$ ve $\beta_{f}$ ifadeleri;

- Farklı $h / B$ oranlarındaki $(h / B=1, h / B=2$ ve $h / B=4)$ yüzeysel kare temelli köprü ayağ (Şekil 5a).

- Farklı $h / B$ oranlarındaki $(h / B=1, h / B=2$ ve $h / B=4)$ yüzeysel dikdörtgen temelli $(L / B=1, L / B=2$ ve $L / B=4)$ köprü ayağı (Şekil 5b).

- Farklı $h / B$ oranlarındaki $(h / B=1, h / B=2$ ve $h / B=4)$ gömülü kare temelli $(D / B=0.5$ ve $D / B=1)$ köprü ayağ (Şekil 5c).

modellerinde hesap edilmiş̧ir. Periyot oranı $(\tilde{T} / T)$ ve temel sönümü $\left(\beta_{f}\right)$ denklemleri içerisinde yer alan değişkenlerin hesabı için literatürde rijit dikdörtgen temeller için tanımlanmış ampirik bağıntılar kullanılmıştır [4]. Bu bağıntılar yüzeysel temellerde titreşim modunun $x$ doğrultusunda Tablo 1'de $y$ doğrultusunda Tablo 2'de ve gömülü kare temeller için Tablo 3'de verilmiştir. Parametrik çalışmalardaki temel sönümü hesaplarında $\left(\beta_{f}\right)$, zemin ortamının sönümü olarak sadece geometrik sönüm $\left(\beta_{x}, \beta_{y}, \beta_{x x}\right.$ ve $\left.\beta_{y y}\right)$ göz önünde bulundurulmuş ve zemin histeresiz sönümü $\beta_{s}=0$ alınmıştır. 
Tablo 1. Dikdörtgen yüzeysel bir temelin $(L \geq B) x$ doğrultusundaki titreşim modu için kullanılan bağıntılar [4].

\begin{tabular}{cc}
\hline $\begin{array}{c}\text { x ekseni boyunca ötelenme } \\
K_{x}=\frac{G B}{2-v}\left[6.8\left(\frac{L}{B}\right)^{0.65}+2.4\right]\end{array}$ & $K_{y y}=\frac{G B^{3}}{1-v}\left[3.73\left(\frac{L}{B}\right)^{2.4}+0.27\right]$ \\
$\alpha_{x}=1$ & $\alpha_{y y}=1.0-\left[\frac{0.55 a_{0}^{2}}{\left.\left(0.6+\frac{1.4}{(L / B)^{3}}\right)+a_{0}^{2}\right]}\right.$ \\
$\beta_{x}=\left[\frac{4(L / B)}{\left(K_{x} / G B\right)}\right]\left[\frac{a_{0}}{2 \alpha_{x}}\right]$ & $\beta_{y y}=\left[\frac{(4 \Psi / 3)(L / B)^{3} a_{0}{ }^{2}}{\left(\frac{K_{y y}}{G B^{3}}\right)\left[\left(\frac{1.8}{1+1.75(L / B-1)}\right)+a_{0}{ }^{2}\right]}\right]\left[\frac{a_{0}}{2 \alpha_{y y}}\right]$
\end{tabular}

Tablo 2. Dikdörtgen yüzeysel bir temelin $(L \geq B)$ y doğrultusundaki titreşim modu için kullanılan bağıntılar [4].

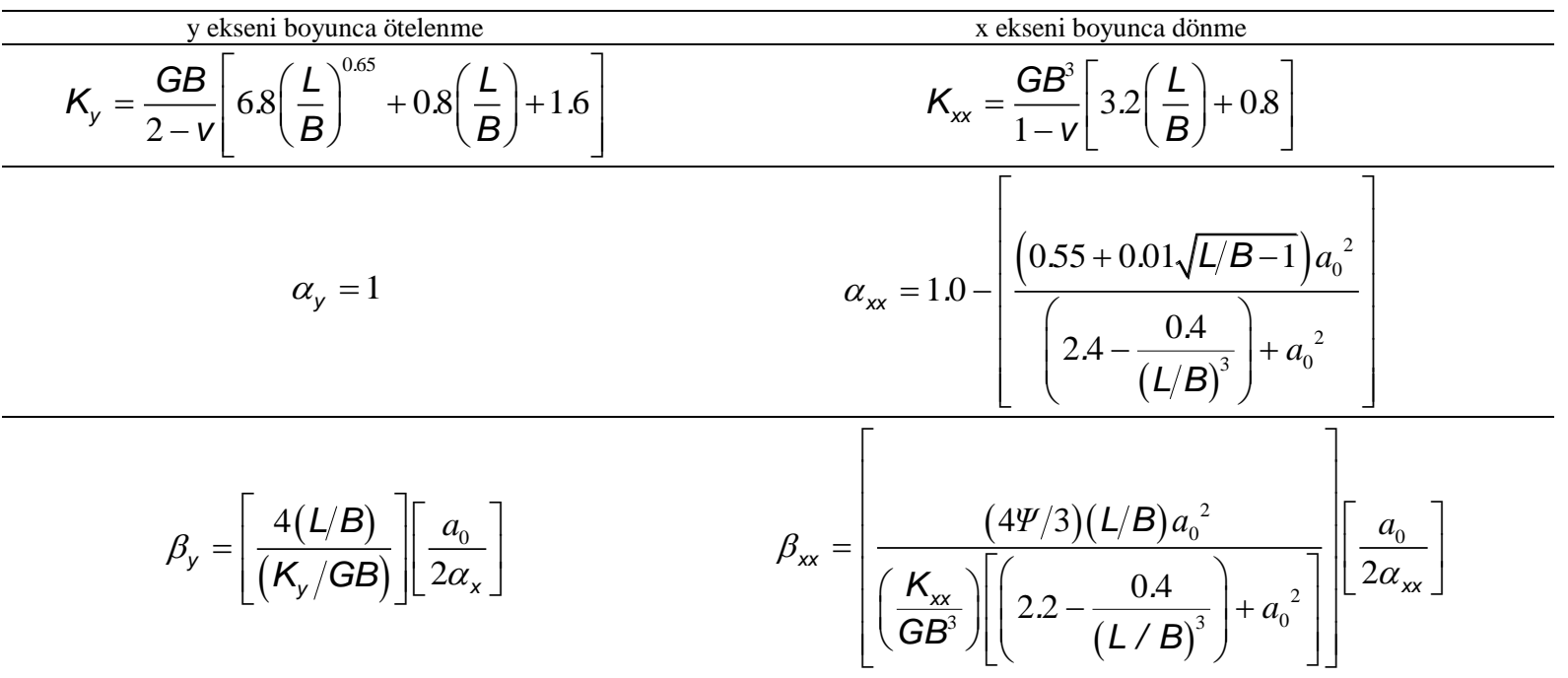


Tablo 3. Gömülü bir kare temelin $(L=B) x$ doğrultusundaki titreşim modu için kullanılan bağıntılar [4].

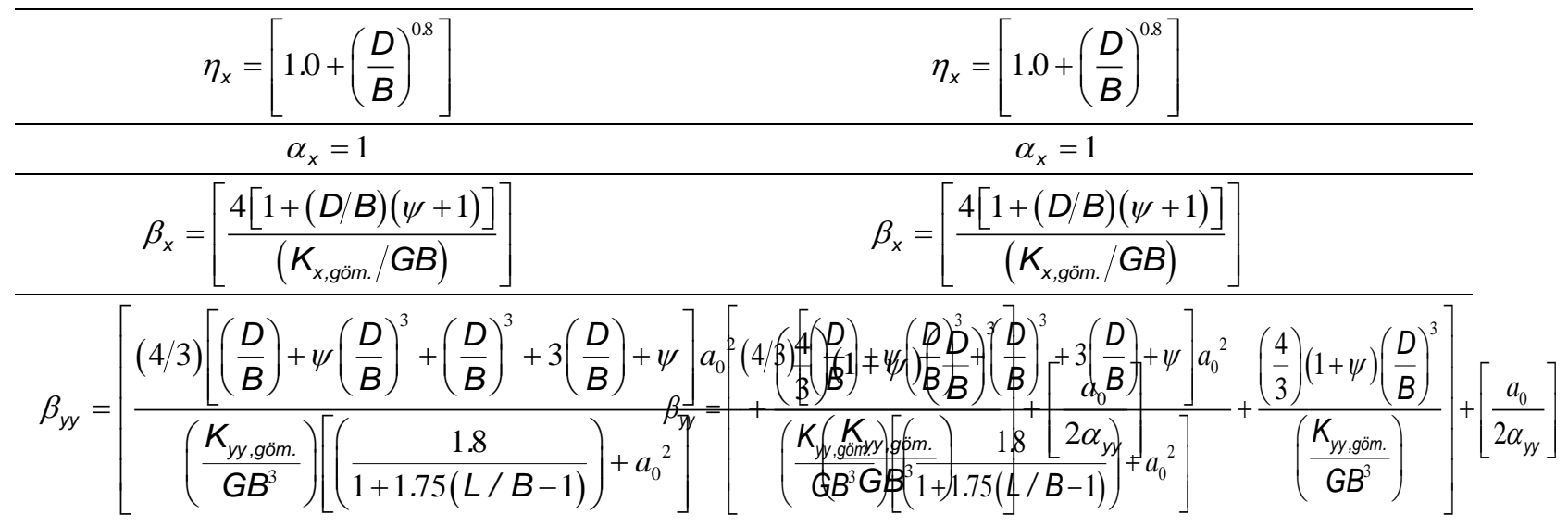

Not: Her bir titreşim modu için gömülü temelin statik rijitliği $K_{i, g o ̈ m . ~}=\eta_{i} K_{i}$

Tablo 1, Tablo 2 ve Tablo 3 'deki $\psi \leq 2.5$ olması şartıyla aşağıdaki şekilde ifade edilir:

$\psi=\sqrt{2(1-v)(1-2 v)}$

Parametrik çalıșmada uygulanan çözüm adımları:

- Farkl1 $h / B(h / B=1, h / B=2$ ve $h / B=4)$ ve $L / B(L / B=1$, $L / B=2$ ve $L / B=4)$ oranlarında üstyap1 kütlelerinin hesab1 $\left(m /\left(\rho_{s} 4 B L h\right)=0.15\right)$.

- Belirli bir aralıkta tanımlanan $h /\left(V_{s} T\right)$ oranlarından herhangi bir kayma dalga hızı $\left(V_{s}\right)$ için rijit tabanlı yapı sistemi periyotlarının $(T)$ elde edilmesi.

- Elde edilen her bir rijit tabanlı periyotlara $(T)$ karşılık gelen rijitliklerin bulunması

- Esnek tabanlı yapı periyotlarının $(\tilde{T})$ hesabı için iterasyonların yapılması.

- İterasyonlar sonucunda hesap edilen periyotlara karşılık gelen titreşim frekansınlarında; dinamik rijitlikler $\left(k_{x}, k_{y y}, k_{y}\right.$ ve $\left.k_{x x}\right)$, periyot oranları ve geometrik sönümlerin $\left(\beta_{x}, \beta_{y y}, \beta_{y}\right.$ ve $\left.\beta_{x x}\right)$ elde edilmesi ve bunlara bağlı olarak temel sönümünün $\left(\beta_{f}\right)$ bulunmasi.

Farklı temel tip (yüzeysel veya gömülü) ve geometrilerine (kare veya dikdörtgen) sahip köprü ayağı modellerinin temel sönümü $\left(\beta_{f}\right)$ hesaplarında $h / B$ ve $L / B$ oranlarının etkisi Şekil 4'de verilmiştir.
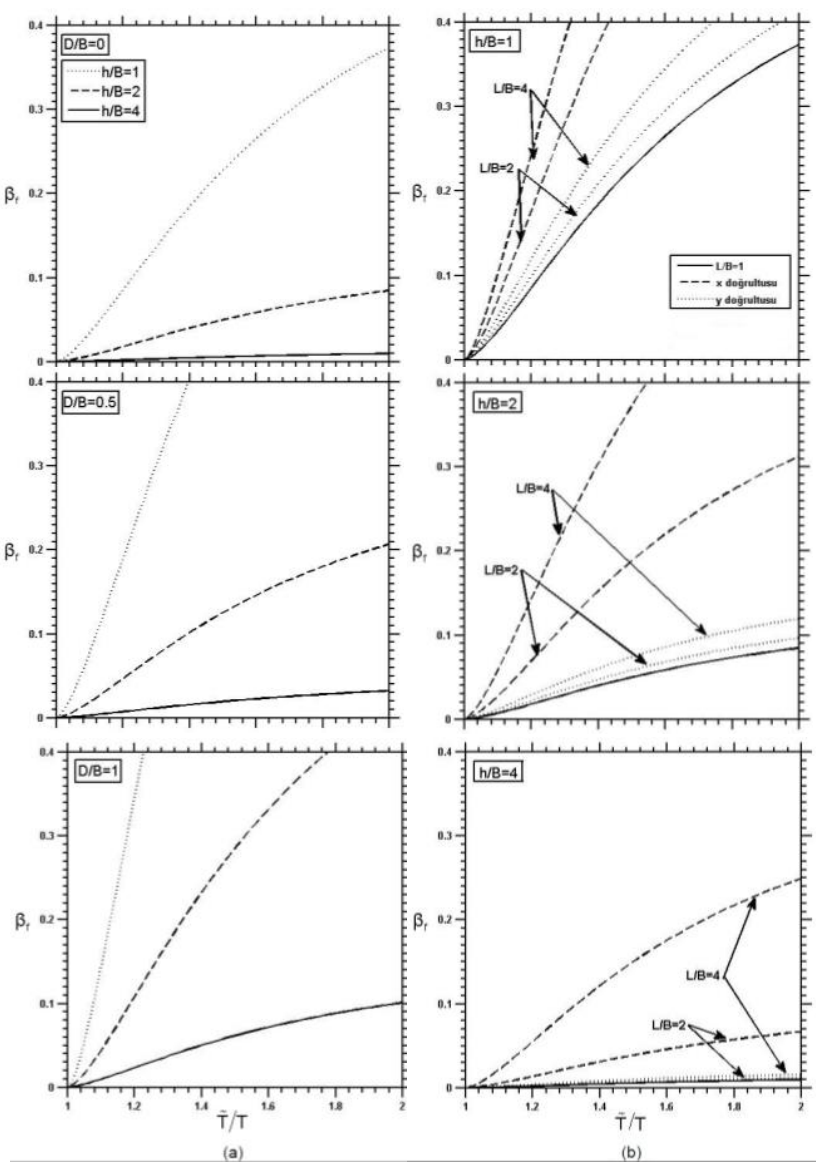

Şekil 4. Farklı temel tip ve geometrilerine sahip köprü ayağı modellerinde temel sönümü: (a) yüzeysel ve gömülü kare temel (b) yüzeysel dikdörtgen temel

- A $h / B$ oranının artması durumunda temelde dönme hareketi hakimiyet kazanır ve bu durumda hesap edilen temel sönüm $\left(\beta_{f}\right)$ değerleri azalır. Yapılar narinleştikçe $\beta_{f}$ değerinin azalmasının nedeni, dönme titreşim modunda geometrik sönüm $\left(\beta_{y y}\right)$ etkisinin küçük olmasından kaynaklanmaktadır. Yüzeysel 
temelden gömülü temele geçilmesi durumunda, temel dönme hareketi doğal olarak daha çok kısıtlanmaktadır. Buna bağlı olarak $\beta_{f}$ değerlerinde artma meydana gelmektedir (Şekil 4a).

- Temelin dikdörtgen olması yapı-zemin etkileşim problemlerinde ilave olarak titreşim doğrultusunun önemini ortaya çıkarmaktadır. Titreşim yönünün etkili olduğu uzun doğrultu (x doğrultusu) kısa doğrultudan (y doğrultusu) daha fazla temel sönümü üretmektedir. $\mathrm{Bu}$ durumun sebebi $\mathrm{x}$ doğrultusunun dönme eylemsizliğinin y doğrultusundan daha büyük olmasıyla açıklanabilir (Şekil 4b).

\section{SONUÇLAR}

Yapının mesnetlendiği zemin ortamı yumuşadıkça geometrik (radyasyon) ve malzeme sönümüne bağlı tüketilen sismik enerji, eylemsizlik kuvvetlerine bağl1 temelde dönme ve ötelenme yerdeğiştirmeleri yaptırarak sisteminin sönüm değerini artırmaktadır. Yapı temelinde sönüm değerinin artmasıyla sisteminin periyodu uzayarak yapının dinamik davranışı önemli derecede değişmektedir. Özellikle depremselliği yüksek bölgelerde zayıf zemin koşullarında inşa edilecek rijit yapıların sismik analiz sürecine yapı-zemin etkileşimini katmak yapıların deprem güvenliği açısından önem kazanmaktadır.

\section{KAYNAKLAR}

[1] J. P. Wolf and C. Song Finite-Element Modeling of Unbounded Media, England, Wiley; 1996.

[2] E. Celebi, F. Goktepe, and N. Karahan, 'Non-Linear finite element analysis for prediction of seismic response of buildings considering soilstructure interaction " Natural Hazards and Earth System Sclences, Vol. 12, pp. 3495-3505, 2012.

[3] P. Galvín A. Romero, 'Technical Note A MATLAB Toolbox for SoilStructure Interaction Analysis with Finite and Boundary Elements"' Soil Dynamics and Earthquake Engineering, Vol. 57, pp. 10-14, 2014.

[4] A. Pais and E. Kausel, "Approximate Formulas for Dynamic Stiffnesses of Rigid Foundations", Soil Dynamics and Earthquake Engineering, Vol. 7, No. 4, pp. 213-227, 1988.

[5] G. Mylonakis, and G. Gazetas, "Seismic Soil-Structure İnteraction: Beneficial or Detrimental", Journal of Earthquake Engineering, Vol. 4, pp. 377-401, 2000.

[6] G. Mylonakis, S. Nikolaou and G. Gazetas 'Footings Under Seismic Loading Analysis and Design Issues with Emphasis on Bridge Foundations", Soil Dynamics and Earthquake Engineering, Vol. 26, pp. 824-853, 2006.

[7] E. Celebi and A.N. Gunduz, "An Efficient Seismic Analysis Procedure for Torsionally Coupled Multistory Buildings Including Soil-Structure Interaction", Journal of Engineering Environmental Sciences, Vol. 29, pp. 143-157, 2005.

[8] NIST GCR 12-917-21, Consultants Joint Venture, Soil-Structure Interaction for Building Structures, U.S. Department of Commerce National Institute of Standards and Technology; 2012.

[9] FEMA 440, Improvement of Nonlinear Static Seismic Analysis Procedures, Prepared by the Applied Technology Council for Federal Emergency Management Agency, Washington, D.C., USA; 2005.

[10] A. S. Veletsos and J. W.Meek, 'Dynamic Behavior of BuildingFoundation Systems" Earthquake Engineering and Structural Dynamics, Vol. 3, pp. 121-138, 1974.

[11] A. S. Veletsos and V.V. Nair "Seismic interaction of structures on hysteretic foundations", Journal of Structural Engineering, Vol. 101, pp. 109-129, 1975.
[12]J. Bielak, "Dynamic Behavior of Structures with Embedded Foundations", Earthquake Engineering and Structural Dynamics, Vol. 3, pp. 259-274, 1975.

[13] J. P. Stewart, G. L. Fenves and R. B. Seed, "Seismic Soil-Structure Interaction in Buildings II: Empirical Findings", Journal Geotechnical and Geoenvironmental Engineering, Vol. 125, pp. 38-48, 1998.

[14] J.P. Wolf Dynamic Soil-Structure Interaction, Prentice-Hall, Upper Saddle River, New Jersey; 1985.

[15] M. J. Givens Dynamic Soil-Structure Interaction of Instrumented Buildings and Test Structures, Ph.D. Thesis, University of California, Los Angeles, The United States Dissertation; 2013

[16] J. E. Luco and R. A. Westmann, 'Dynamic Response of Circular Footings", Journal of Engineering Mechanics, Vol. 97, No. 5, pp. 13811395, 1971.

[17] A. S. Veletsos and Y. T. Wei, "Lateral and Rocking Vibrations of Footings", Journal of Soil Mechanics and Foundations Division, Vol. 97, No. 9, pp. 1227-1248, 1971 